\title{
Commentary: "Sleep quality is inversely related to body mass index among university students"
}

\author{
Tingting Li1 $\odot$, Xu Zhang ${ }^{1} \oplus$, Baohong Xue ${ }^{1 *}$ ()
}

\section{Dear Editor,}

We read with great interest the study of Jun Wang et al. ${ }^{1}$ in which they demonstrated the relationship between sleep quality and BMI among university students. The authors indicate that the prevalence of obesity is higher in males than in females, and the sleep quality of female students may be related to body mass index.

Firstly, it is of great significance ${ }^{2}$ for college students to research the relationship between sleep quality and body mass index. Studies had shown that the poor sleep quality among female students may be related to multiple factors ${ }^{3}$. The relationship between sleep quality and BMI in females needs to be further explored. And there is a small sample size of different groups in the present study. Thus, more samples should be recruited in a future study.

Secondly, the authors used a cross-sectional study and were unable to explore causality further. Therefore, further longitudinal studies are needed to investigate the relationship between sleep quality and body mass index in college students and to develop appropriate interventions for high-risk groups.

\section{AUTHORS" CONTRIBUTION}

TL: Conceptualization, Data curation, Writing-original draft. XZ: Formal analysis, Writing-original draft. BX: Supervision, Validation, Visualization, Writing-review \& editing.

\section{REFERENCES}

1. Wang J, Chen Y, Jin Y, Zhu L, Yao Y. Sleep quality is inversely related to body mass index among university students. Rev Assoc Med Bras (1992). 2019;65(6):845-50. https:// doi.org/10.1590/1806-9282.65.6.845

2. Meurling IJ, Shea DO, Garvey JF. Obesity and sleep: a growing concern. Curr Opin Pulm Med. 2019;25(6):602-8. https://doi.org/10.1097/MCP.0000000000000627

3. Saygın M, Öztürk Ö, Gonca T, Has M, Hayri UB, Kurt Y, et al. Investigation of sleep quality and sleep disorders in students of medicine. Turk Thorac J. 2016;17(4):132-40. https://doi.org/10.5578/ttj.30513 